\title{
ORTEGA Y GASSET, FILÓSOFO DE LA CIENCIA
}

\section{ORTEGA Y GASSET, PHILOSOPHER OF SCIENCE}

\author{
JESÚS RUIZ FERNÁNDEZ \\ UNED
}

Resumen: Aunque ignorado por lo común en este campo, Ortega y Gasset posee una filosofía de la ciencia de gran actualidad. No hay más que ver que en 2006 Ronald Giere, uno de los más destacados filósofos de la ciencia actuales, publica una obra con el título de Scientific Perspectivism. El presente trabajo quisiera prolongar los estudios sobre Ortega en este terreno, a partir de una interpretación de la «razón vital» basada en la fenomenología, la psicología cognitiva y la filosofía constructivista de la ciencia. A las concomitancias que se le han encontrado con Dilthey y la hermenéutica en su filosofía de las ciencias humanas, y con Popper y Kuhn en la filosofía de las ciencias naturales, quisiera ańadir su afinidad con Feyerabend, autor a quien le acerca su «liberalismo» cultural.

Palabras clave: Dilthey, Weyl, Popper, Kuhn, Feyerabend, Giere.

АвSTRACT: Despite having been generally ignored in this field, Ortega y Gasset has a remarkably relevant philosophy of science. It is sufficient to see that in 2006 Ronald Giere, one of the most outstanding current philosophers of science, published a work titled Scientific Perspectivism. This work tries to continue studies about Ortega in this field, from an interpretation of «Vital Reason» based on phenomenology, cognitive psychology and constructivist philosophy of science. In addition to the concomitances found in Dilthey and the hermeneutics in his Philosophy of Human Sciences, and in Popper and Kuhn in the Philosophy of Natural Sciences, I would like to add his affinity with Feyerabend, an author to whom his cultural «Liberalism»brings him close.

KeYwords: Dilthey, Weyl, Popper, Kuhn, Feyerabend, Giere.

1 E-mail: jruizfer@madrid.uned.es jjesusruizz@hotmail.com 


\section{La actualidad de Ortega y Gasset}

A pesar de contar ya con algunos estudios en esta dirección, Ortega y Gasset no suele ser contemplado por la crítica como filósofo de la ciencia. Sin embargo lo es, y en alto grado. Su propósito fundamental fue dotar a las ciencias humanas de una base filosófica con que sacarlas del estancamiento en que el filósofo español veía una de las causas de los males que asolaban a la humanidad (VIII, 73). Las ciencias naturales fueron fundamentadas filosóficamente en la Edad Moderna; y esta fue la razón de su enorme desarrollo, que, gracias a la técnica, se ha concretado en las fabulosas comodidades materiales de que gozamos; pero no ocurrió lo mismo con las ciencias humanas.

Por otra parte, lo que la filosofía moderna de la ciencia no había previsto, ni podía prever, fue la llamada crisis de principios de las ciencias de inicios del siglo XX. En efecto, ¿si la ciencia es absoluta, una e inmutable, cómo explicar una revolución científica de tal calibre, un cambio de paradigma de tal alcance? Éste fue el segundo problema con que se encontró Ortega como filósofo de la ciencia. Pero en realidad era el mismo desde otra perspectiva, y ambos abocaban a lo que fue su problema fundamental.

El problema fundamental de Ortega es el de reformar la idea tradicional de razón - o ciencia, pues identificaba ambos términos - para que en ella tuviera cabida la vida. La nueva idea que la "crisis de fin de siglo», la mudanza de época, la irrupción de la Edad Contemporánea, había puesto en primer plano, con sus notas de relatividad, pluralidad y cambio. El error moderno, y causa de la paralización de las ciencias humanas, fue el considerar al hombre un ser natural más. Su objeto debería variar; pero esta rectificación habría de afectar también a las mismas ciencias naturales, pues, en la medida en que están hechas por hombres, debería hallar en ellas un hueco la relatividad, pluralidad y cambio.

Siguiendo a Husserl, Ortega propugnó la unidad de la ciencia, así como la extensión del método clásico de las ciencias naturales a las ciencias humanas; pero con una importante corrección, pues su método debería ser vital: la razón vital. A esto lo llamó Ortega el tema de nuestro tiempo, tema que, al parecer, sigue siendo del nuestro, ya que cuando nos encontramos con obras tan recientes como Scientific Perspectivism de Ronald Giere, uno de los más eminentes filósofos de la ciencia actuales, es fácil deducir, ya por el mismo título, que el problema del libro es el mismo que el del filósofo español. No es de extrañar que haya sido reivindicado para Ortega un lugar más destacado en las Historias de la ciencia, 
donde figura todo lo más como pionero de la filosofía de la técnica (Martínez Bonati, 2000, 7).

El perspectivismo de Ortega y Gasset fue el resultado de una reforma de la idea de ser, por la que éste se transmuta de sustancia en perspectiva. La razón vital, por su parte, será el modo de pensar que tiene como objeto este ser perspectivístico. La razón nació en el siglo VI a.C., diferenciándose de todas las demás formas de pensar — de la religión, por ejemplo—en que prueba las cosas. La ciencia nos dice por qué ocurren los hechos, esto es, lo que las cosas son. Su objeto siempre ha sido el ser; pero, ahora, el ser parmenídeo debía dejar paso al heraclíteo.

Por otra parte, razonar es una cosa que se puede hacer con más o menos rigor, con mayor o menor perfección. En este sentido, Ortega distinguió tres formas de la razón: razón cotidiana, científica y filosófica. En este artículo me ocuparé especialmente de la razón científica; de las otras dos sólo cuando las comparaciones beneficiaran la comprensión.

Hay varios trabajos sobre la filosofía orteguiana de las ciencias naturales (García Astrada, 1959; Bueno, 2001; Pellicani, 2007), en los que queda suficientemente claro cómo Ortega se inscribe en la tradición antipositivista de Duhem, Poincaré y Weil; corriente antiinductivista que resalta el momento constructivo de la ciencia, que, a juicio de estos autores, no puede reducirse, ni mucho menos, a observación y experimento, como sostenía la filosofía positivista de la ciencia, seguramente como reacción a los excesos constructivistas del idealismo alemán.

A esta acertada interpretación de Ortega, habría que añadir la interesante referencia de Manuel Garrido (1983, 316) y Félix Martínez Bonati (7), de que en el filósofo español están los conceptos de paradigma e inconmensurabilidad de las teorías científicas, luego recogidos por Kuhn y Foucault.

Como filósofo de las ciencias humanas, Ortega ha sido estudiado por Mercedes Miquel (1992), quien resalta el uso que en ellas hace el filósofo español del concepto de "comprensión», en contraposición al de "explicación", típico de las ciencias naturales. Pero es de justicia recordar la referencia de J. Molero, de 1981 (45), a que en Las Atlántidas se encuentra tal distinción; que las Historias de la ciencia suelen atribuir a Dilthey, y que, como sabemos, es decisiva en la actual hermenéutica para diferenciar las ciencias naturales de las humanas. 
Gracias a estos trabajos, Ortega está empezando a cobrar nitidez como filósofo de la ciencia. Por mi parte, quisiera añadir las siguientes aportaciones: 1) Resaltar el carácter fenomenológico de la filosofía de la ciencia de Ortega, que, al no haberse tenido en cuenta en los estudios citados, impide diferenciar al filósofo español de los demás autores constructivistas. Porque si las posiciones de éstos conducen fácilmente al relativismo y al subjetivismo, Ortega es firmemente absolutista. 2) Contemplar la filosofía de la ciencia de Ortega incardinada en el conjunto de su filosofía, cuyo núcleo es la razón vital. Lo que nos permitirá, comparando la ciencia con la filosofía y con el modo de razonar común en la vida cotidiana, captar mejor sus peculiaridades. 3) Puesto que ya hay trabajos en orden a relacionar a Ortega con Popper y Kuhn, investigar qué tiene nuestro autor en común con Feyerabend; no sólo para así poder completar el repaso por la «nueva filosofía de la ciencia», sino porque, como es natural, el anarquismo epistemológico de Feyerabend no está lejos en muchos aspectos del liberalismo epistemológico de Ortega y Gasset. 4) Llamar la atención sobre el sorprendente parecido de Ortega con Ronald Giere, que puede darnos idea de la actualidad del filósofo español. Aunque quizás no resulte tan sorprendente la familiaridad, si tenemos en cuenta que Giere llega a su perspectivismo, realista y constructivista, a través de la psicología cognitiva, y Ortega al suyo, también realista y constructivista, por medio de la psicología fenomenológica de su tiempo, antecedente de la psicología cognitiva actual.

Afortunadamente contamos con tres hilos de Ariadna para orientarnos en el laberinto de la razón vital o método de la ciencia de Ortega y Gasset: la fenomenología, la psicología cognitiva y la filosofía de la ciencia antipositivista. En este trabajo me centraré en tres de sus notas esenciales: la veracidad, la intuición y la dialéctica.

\section{Ciencia y verdad}

En sus razonamientos cotidianos el hombre corriente no suele tener mucho interés por la verdad, lo que demuestra que se trata de una razón «débil». Lo difícil en la vida cotidiana es sumergirse en una actitud contemplativa, en la que, liberándose de los prejuicios, intereses, gustos, etc., se examinen, fría y distantemente los problemas, de la manera más objetiva posible. Pero en la ciencia y en la filosofía, utilizaciones más rigurosas de la razón vital, la veracidad es esencial. $\mathrm{El}$ «desinterés» siempre se ha considerado un elemento constitutivo de ambas. El científico real, de carne y hueso, aun entre el cúmulo de sus intereses vitales, 
se siente también implicado en algo así como «buscar la verdad», ha podido constatar Ronald Giere en sus investigaciones a pie de obra en sus visitas a las instalaciones del ciclotrón en Indiana $(1988,17)$.

Husserl resaltó el momento de la epojé en la ciencia. Que Ortega tradujo por «ensimismamiento», porque

sólo se entera uno de lo que son las cosas en la medida que las contempla. El interés nubla la contemplación haciéndonos tomar partido, cegándonos para lo uno, mientras derrama un exceso de luz sobre lo otro. La ciencia adopta, desde luego, esta actitud contemplativa, resuelta a no hacer más que espejar castamente la fisonomía multiforme del cosmos (III, 404).

Que la verdad es esencial a la ciencia, se aprecia, además, en que nace con ella. En efecto, la verdad es ajena a las demás formas de pensamiento. En el pensamiento precientífico, incluso en la religión en su forma actual, no hay conciencia de la verdad ni del error ni problema gnoseológico alguno. Los hombres creen en los dioses no porque sea verdad que existan: creen y punto (Ortega, 1994, 206, 210-211).

La nueva filosofía de la ciencia ha insistido en la importancia que el «contexto de descubrimiento» tiene en la labor científica. A Ortega no se le escapaba, por supuesto, el hecho del peso que la vida real tiene en el laboratorio. Cuando escribía, por ejemplo, que «se hace política en los laboratorios» y que «el químico y el histólogo llevan a sus experimentos un secreto interés electoral» (II, 16), sabía muy bien de lo que hablaba. Es muy conocido el episodio del enfrentamiento de Galileo con la Iglesia, y muchos creen que con romper la ciencia sus ataduras con esta institución ya está hecho todo; no se dan cuenta de que mucho más peligrosas son las ataduras internas. Pero Ortega, aun con todo, confiaba en que algo se podía hacer. La ciencia es un ideal, y como todo ideal es imposible de cumplir; pero, por lo menos, puede servirnos como idea regulativa. «Hay que libertar la ciencia de los prejuicios del hombre científico, de aquellas perturbaciones que a la pura intelección traen los amores y odios políticos, estéticos, económicos y en general vitales del hombre científico» (XII, 363). Como es sabido, la sociología de la ciencia actual es hija de la teoría de las ideologías de Marx, pero, según el filósofo español, el hombre es capaz de liberarse de sus condicionamientos ideológicos, como Marx mismo (IV, 83).

Lo mejor, según Ortega, es adoptar una actitud natural; una actitud que, aun a sabiendas de que siempre se está cerniendo sobre nosotros la amenaza 
de la ideología — «queramos o no, flotamos en ingenuidad, y el más ingenuo es el que cree haberla eludido» (IV, 32)—, no llega ésta a obsesionarnos. ¿Cuántas veces se ha llegado a paralizar la ciencia por culpa de este exceso de celo? «Cautela, pero sin suspicacia; con naturalidad» (VII, 328) es la divisa del filósofo madrileño. ¿Cómo no recordarnos estas palabras aquellas otras de Paul Feyerabend de que en filosofía de la ciencia «todo lo que se necesita es menos moralismo menos seriedad, menos interés por la verdad [...] una actitud más lúdica» $(1974,167)$.

El ludismo recorre toda la obra de Ortega, un autor que presumió de ser de los pocos entre sus contemporáneos que percibía un viraje en la historia hacia un sentido deportivo y festival de la vida. Pues «la cultura brota y vive, florece y fructifica en temple espiritual bien humorado —en la jovialidad [...] el estado de ánimo en que suele estar Jove- Júpiter» (VII, 348). Hay un lado clasicista y humanista en la filosofía de Ortega, un temple que le hace estar mirando continuamente hacia Grecia. Donde la filosofía tenía el estilo competitivo de los juegos: "como se juega al disco y al pancracio, se juega a filosofar» (VIII, 305). Incluso Platón se plantea si el chaquete y las ciencias no son cosas diferentes (VIII, 306). Ortega siempre pensó que la ciencia, la filosofía son juegos, un «sentir fruición en el tejemaneje de las ideas, en jugar a la exactitud de los conceptos» (VIII, 296).

Hay en el filósofo y en el científico «una fruición de "descifrador de enigmas" en que, por lo pronto, pierde el enigma todo el carácter que per accidens puede envolver y lo empareja con el jeroglífico, la charada y las palabras cruzadas» (III, 307):

Los hechos vienen a ser, pues, como las figuras de un jeroglífico. ¿Han reparado ustedes en la paradójica condición de tales figuras? Ellas nos presentan ostentosamente sus clarísimos perfiles, pero ese su claro aspecto está ahí precisamente para plantearnos un enigma, para producir en nosotros confusión. La figura jeroglífica nos dice: ¿Me ves bien? Bueno, pues eso que ves de mí no es mi verdadero ser. Yo estoy aquí para advertirte que yo no soy mi efectiva realidad. Mi realidad, mi sentido está detrás de mí, oculto por mí. Para llegar a él tienes que no fiarte de mí, que no tomarme a mí como la realidad misma, sino, al contrario, tienes que interpretarme y esto supone que has de buscar como verdadero sentido de este jeroglífico otra cosa muy distinta del aspecto que ofrecen sus figuras $(\mathrm{V}, 15)$. 


\section{Más allá del constructivismo}

Otro momento del método orteguiano de la ciencia, de la razón vital, es la «intuición». Los intérpretes de Ortega — Gustavo Bueno, Luciano Pellicani-, al destacar el carácter constructivo e inventivo de su idea de la ciencia, han pasado por alto el hecho de que en nuestro filósofo construcción es a la vez, y aunque parezca contradictorio, intuición. Intuición que salva a la construcción del relativismo. La aparente contradicción se desvanece si atendemos a la etimología de inventar, que deriva de invenio, hallar (IV, 366). Pero otra buena manera de comprender la integración de ambos conceptos es atendiendo a los experimentos de Köhler. Ortega conocía bien aquellos estudios, a los que dedicó un artículo, «La inteligencia de los chimpancés», con motivo de la visita que el científico hizo a Madrid (III, 574-579). Köhler propuso la teoría de la intuición —einsichtcomo alternativa al método de ensayo y error de Thornodike para la solución de problemas. No solucionamos los problemas, a juicio de Köhler, por ensayo y error, a la manera como el gato de Thorndike salía de la jaula: realizando a la desesperada todo tipo de movimientos, hasta que, por fin, casualmente, tocaba la aldaba y se abría la puerta; sino más bien como Sultán, el chimpancé, a quien, ensimismado en un rincón, se le «encendía una lucecita», y sin titubear apilaba las cajas para llegar a la ristra de plátanos.

¿En qué consiste esta «chispa de intelección» del chimpancé? En que nuestro hermano primate, con los elementos que tenía a mano — las cajas, los frutos, él mismo - ha construido una imagen en la que se «ve» alcanzando los plátanos. Una imagen compleja donde los elementos están dispuestos de manera diferente a como aparecen en la percepción empírica. Esta construcción es la intuición. Así es como solucionamos nuestros problemas en la vida cotidiana, en la ciencia, en la filosofía. Aparece un hecho que no encaja en la idea que tenemos de una cosa - la ristra de plátanos está demasiado alta, en el caso del chimpancé- y, entonces, tenemos que reestructurar los elementos de la idea para que encaje. Una vez dentro, el nuevo hecho tiene sentido, lo entendemos.

Es por lo que Ortega comparaba la razón y la solución de problemas con los rompecabezas (VII, 344). De lo que se trata es de si «unas ideas [...] casan o no entre sí, y tratándose de teorías realistas, como la física, si casan además con los hechos» (VIII, 306). De nuevo aparece aquí el carácter lúdico de la ciencia. Pero, aparte de percatarnos de que lo que hace Ortega es exponer el mecanismo mental que investigan la psicología cognitiva y el constructivismo psicológico, merece la pena, también, resaltar que este momento constructivo de la intuición no implica 
para nada el relativismo. La ciencia en Ortega es constructivista en el mismo sentido que lo es en el "constructivismo realista» de Giere, en el sentido de que el constructo no se nos da en la experiencia empírica, sino que es construido por el científico. Porque los científicos son realistas, como ha observado el filósofo americano en sus investigaciones sobre su proceder espontáneo: realmente creen que hay algo dando vueltas en el ciclotrón $(1988,124)$.

«La ciencia y la filosofía, ¿qué otra cosa son sino fantasía?» (V, 403). Pero por muy imaginativas que sean éstas, no son poesía sin más. «En las ciencias de realidad, como la física o la historia, la fantasía está condicionada, limitada, fecundada por los datos» (VII, 515). O como en la psicología, siendo ésta la razón de la crítica que Ortega hace a Freud. El filósofo español valoró como nadie y antes que nadie la importancia del psicoanálisis, cuyo conocimiento introdujo tempranamente en España; se sirvió de alguna de sus teorías para sus trabajos filosóficos, y alabó la audacia y originalidad sin par de sus hipótesis; pero supo ver, al mismo tiempo, que, si bien algunas de éstas quedarían afincadas en la ciencia, otras parecían, sin embargo, "un poco excesivas y, sobre todo, un bastante caprichosas» (VI, 302). Lo que Ortega critica a Freud es la falta de base empírica de muchas de sus afirmaciones.

Luciano Pellicani en su artículo «Ortega y Popper: trayectorias paralelas», compara a los dos filósofos, detectando en ellos numerosas coincidencias. Pero, lamentablemente, Pellicani no se centra en el "principio de falsabilidad», que es justo lo más representativo de Popper. Lo que ambos tienen en común es su pertenencia a la tradición constructivista de la ciencia, cosa a la que, con respecto a Ortega, ya se había referido Gustavo Bueno seis años antes. Curiosamente, Bueno sostiene que la filosofía de la ciencia del español no habría que ponerla «en la línea del falsacionismto popperiano - Ortega ignoró a Popper-, sino más bien en la línea del constructivismo verificacionista de Weyl» (26-27). Desde luego, Ortega no habla nunca de que haya que proceder sistemáticamente al falseamiento de las hipótesis, sino que lo que da por sentado es que los científicos las verifican. Si bien, insiste en que, cuando un experimento las falsea, se sustituyen por otras. Aunque en Ortega, el principio de falsabilidad de Popper, sería más bien lo que podría llamarse principio de limitación.

Porque, en lo que de ninguna manera el autor español está con Popper, es en que la ciencia se reduzca a mera opinión, o en que las teorías y leyes científicas sean sólo verosímiles. Las construcciones científicas no son opinables ni verosímiles porque, más tarde o más temprano, vayan a ser falsadas, sino que son 
verdaderas. Parcialmente verdaderas, pero verdaderas. El punto débil del conocimiento, de la ciencia, no es su falsedad, sino su simplicidad; el no ser capaz de encerrar nunca la inmensa complejidad de la vida entre las grises paredes de las fórmulas. Pero esto no quiere decir que en cada momento histórico la ciencia sea falsa. No es falsa, sino limitada. Infantil, ingenua, inexperimentada, si se quiere.

Veíamos antes como el problema fundamental de Ortega era el de conciliar una concepción de la ciencia de carácter fenomenológico, absolutista, con el hecho de la evolución histórica de las teorías científicas. Y, también, como su solución era el perspectivismo. Una audaz teoría, de corte fenomenológico, según la cual lo relativo, plural y cambiante no es la ciencia, sino la realidad. La ciencia se mantiene absoluta, una e inmutable en tanto que refleje la realidad relativa, plural y cambiante.

Hay una metáfora, con la que el filósofo español expresa magistralmente su pensamiento: la realidad no tiene una cara en sí, sino que la pone. Y a uno le pone una cara, y a otro le pone otra. La cara que aparece —el «fenómeno» de la fenomenología, la perspectiva - depende de los dos, de la realidad y de nosotros: «la pone ella pero nos la pone a nosotros» (IX, 370). Si para uno es bacía de barbero, para otro es yelmo de Mambrino. Para entender el perspectivismo, ayuda mucho la interpretación que Ortega hizo de la teoría de la relatividad de Einstein. El famoso físico visitó España en 1923, apareciendo al poco «El sentido histórico de la teoría de Einstein", trabajo con el que pretendía poner boca abajo la tópica y desacertadísima, a su juicio, interpretación de la ilustre teoría. La teoría de la relatividad, resultaba ser para Ortega jabsolutista!: «Para la física de Einstein, nuestro conocimiento es absoluto; la realidad es la relativa» (III, 233).

De la misma forma que, con su perspectivismo, encontraba Ortega una alternativa al dogmatismo y al escepticismo, halla Giere, con su «realismo perspectivista», una solución intermedia al objetivismo realista y al constructivismo social. En este perspectivismo, realista e integrador como el de Ortega, las leyes de Newton, constituirían la perspectiva mecánica del mundo; las leyes de Maxwell, la perspectiva electromagnética; la ecuación de Schrödinger, la cuántica, y la selección natural, la perspectiva evolucionista $(2006,14)$. La sierra de Guadarrama, que, en el famoso ejemplo del filósofo madrileńo, ofrece perspectivas distintas y complementarias desde Madrid y Segovia (II, 19), se transforma en el americano en el monumento a Washington, que, visto desde el Capitolio, ofrece una perspectiva, diferente y complementaria, a la que regala cuando es visto desde su base $(2006,13)$. 
Me atrevería, sin embargo, a señalar una diferencia entre ambos perspectivismos, si es que Giere sigue creyendo que la perspectiva es producto de una interacción - «a function of an interaction between the world and human cognitive capacities» $(2006,93)$, cosa que puede apreciarse en su interpretación de la percepción del color, interpretación que hace extensiva a toda percepción y al conocimiento en general: «el hombre ve los objetos coloreados debido a una compleja interacción entre la forma como los objetos reflejan la luz que incide sobre ellos y la forma como el sistema visual humano procesa esa luz reflejada» $(2006,124)$. Es decir, que para Giere hay en el mundo ciertas cualidades «ocultas», objetivas e independientes del sujeto, algo así como una cara real, que al interaccionar con nuestro aparato cognoscitivo produce la perspectiva, la cara que nos pone. Pero es muy difícil, con una postura epistemológica así, eludir el relativismo- en efecto, una cosa sería el mundo objetivo, y otra la interacción relativa. En Ortega — que, por cierto, también pone el ejemplo del color (III, 198)_, la única realidad es la perspectiva. No es que el mundo interaccione con nosotros produciendo la perspectiva; lo que interacciona es la misma perspectiva.

Hace muchísimo tiempo que el hombre, en lugar de comerse un plátano como el mono de Kölher en Canarias, se comió una manzana. Y, según parece, fue expulsado del paraíso. Del paraíso que era la razón pura, a la vida de la razón vital. A los problemas. Pues «nada es vivo sino en la medida en que es y sigue siendo problema, y esto vale, no sólo para la vida teorética, sino para todos los demás órdenes» (IV, 53). Y es que siempre hay algo que no encaja con las ideas que nos hacemos de las cosas; parece que la realidad se complace en contradecirnos. ¿Cómo no, si solamente somos conscientes de ella cuando nos falla, cuando nos es infiel? Sólo me doy cuenta de que tengo muelas cuando me duelen. Por eso, la creencia inconsciente, lo que Ortega llama "contar con», es el paraíso; la duda, la desorientación, en cambio, es la expulsión del paraíso, esto es, este mundo, el «valle de lágrimas». Como cuando se desespera don Quijote, al constatar que en sus aventuras es como si los encantadores se hubieran puesto de acuerdo en estorbar los unos lo que hacen los otros: «todo este mundo es máquinas y trazas, contrarias unas de otras. Yo no puedo más» (II, XXIX).

\section{Ciencia y progreso}

Sin embargo, ninguno de los problemas con los que se ha encontrado la humanidad hasta ahora se ha llegado a resolver del todo. Es por esto que «la ciencia es un proceso siempre fluyente y abierto hacia la solución — no es, pues, 
de hecho, la arribada a la costa anhelada-, sino que es la navegación procelosa hacia ella» (VII, 321). Y es que la dialéctica anidaba como un gusano en la manzana del paraíso.

Es curioso que en las exposiciones de la fenomenología de Husserl no suela aparecer la dialéctica junto a la epojé, la reducción eidética, la intuición y la evidencia. Desde luego, Ortega —a quien más de una vez se ha acusado de ocultar sus fuentes- bien claro nos dice que la tomó de Husserl (VII, 453; VIII, 273, IX, 351; Ortega, 1994, 66). Aparte de que el método dialéctico aparece por primera vez en la obra de Ortega en «Sobre el concepto de sensación», artículo de 1913, con el que pretendía introducir la fenomenología en España (I, 250). Y bien claro es, además, al negar que lo tomara de Hegel. La dialéctica de Hegel es una camisa de fuerza que se pone a las cosas, que pareciera que no pueden sino seguir el camino que el loquero les indica (XII, 388; II, 299; IV, 25-26; IX, 359; XII, 262-263; VII, 453). Pero para Ortega «es la cosa el maestro del hombre» (IX, 368) y hay que dejarla a ella que hable y nos cuente su propia dialéctica; sólo hay que escuchar su voz, por más que, al ser una voz silente, sólo pueda oír el hombre ensimismado.

Lo que está proponiendo aquí Ortega es un método natural, en lugar de un método camisa-fuerza hegeliano o del tipo que sea. Como Giere, cuando, desde su "naturalismo científico», critica el bayesianismo, porque los científicos ni utilizan ni saben lo que es el teorema de Bayes (Callebaut, 1993, 176). Feyerabend, el autor que más ha escrito contra el método científico, no niega la existencia de reglas en la ciencia, sino que, como buen anarquista, lo que niega son las reglas artificiales, en beneficio de las reglas naturales, espontáneas. En este autor, la ciencia no es caótica; hay reglas, aunque no abstractas, sino que surgen del proceso mismo de la investigación. Al tópico de la identificación del anarquismo con el caos, ya contestó lapidariamente Eliseo Reclus: «el anarquismo es la máxima expresión del orden». Pero, lo cierto, es que un autor que escribe que «la ciencia es incoercible e irreglamentable» (IV, 351), «insumisa al albedrío y ante la cual solo cabe por parte del mismo creador una humilde actitud pasiva» (XII, 243), no puede estar lejos de la posición epistemológica de Feyerabend. La crítica que hace éste al método camisa-fuerza popperiano es la crítica que hace Ortega al método camisa-fuerza hegeliano. Pues, como escribe Feyerabend, después de haber puesto de manifiesto que no hay una sola regla que los científicos no se hayan saltado: «Esta práctica liberal [...] no es meramente un hecho de la historia de la ciencia. Ni una simple manifestación de la ignorancia e incons- 
tancia humanas. Es razonable y absolutamente necesaria para el desarrollo del conocimiento» $(1974,16)$.

Este liberalismo, compartido por ambos, va a hacer que sus posiciones en filosofía de la ciencia estén próximas. En el artículo de 1926, «La querella entre el hombre y el mono», propone Ortega el «principio de proliferación» de teorías de Feyerabend:

Dentro de la ciencia, toda teoría, aun la más firme, se presenta siempre con un índice de problematismo, de mera aproximación a la verdad ejemplar y única. Jamás excluye otras posibilidades en parte antagónicas. Esta endeblez de toda teoría científica es una de sus virtudes, tal vez la que más la diferencia de un dogma. Merced a ella, es elástica, y deja margen a la multiplicidad de puntos de vista y de innovaciones [...] Si, como he dicho, es característico de la estricta teoría científica su posible convivencia con otras teorías que contradicen aquélla, en cambio, hay siempre en la ciencia — como en la política- un partido, una teoría que ocupa el poder. Esta, que podemos llamar teoría canónica, impera siempre sobre las mentes menos inquietas y creadoras. Es la opinión más «seria», es decir, la menos genial e inteligente [...] Cultura es, frente a dogma, discusión permanente. Por esta razón conviene presentar frente a la idea canónica la revolucionaria. Conviene, conviene la herejía — como en la Iglesia — en la ciencia. (III, 552-557).

Ortega nos presenta la dialéctica, al igual que todas sus grandes ideas filosóficas, como perogrullada. Es lo que llama el fenómeno de la absorción o superación, «tan claro y reiterado que no ofrece lugar a duda» (IX, 359) — como se ve, el razonamiento cotidiano. Se trata simplemente de que la idea antigua resulta, a la vez, abolida y conservada en la nueva. Pues «al revés que en la vida de los cuerpos, en la vida del espíritu las ideas nuevas, las ideas hijas llevan en el vientre a sus madres» (VII, 370). Por eso hay un Einstein, porque antes hubo un Newton, y, antes, la teoría del impetus del siglo XIV y antes Aristóteles. Lo mismo que hay un Feyerabend porque antes hubo un Popper, y anteriormente la Escuela de Viena. Pretender ser un Robinson en ciencia es como querer plantar una choza en la Puerta del Sol (I, 229). A Einstein se le ocurrió la feliz idea de la teoría de la relatividad gracias a que en la teoría de la gravitación universal no encajaba el electromagnetismo; pero ya llegará a Einstein su hora (VIII, 85).

La ciencia en Ortega "evoluciona como un organismo» (XII, 471). Como en Giere, cuyo estudio cognitivo de la ciencia se basa en la teoría de la evolución 
(1988, XVII). O en Philip Kitchert, otro representante destacado del «naturalismo científico»:

El principal argumento que presenta Kitcher para ·rehabilitar la noción de verdad va dirigido especialmente contra la llamada «inducción pesimista», que afirma que casi todas las teorías que en su día fueron exitosas - p. ej., la astronomía de Ptolomeo, la teoría del calórico, la teoría del éter electromagnético, etc. - han terminado siendo abandonadas, y mostrándose que sus términos centrales no poseían referencia real. A esta generalización histórica podemos oponerle, según Kitcher, una «inducción optimista», según la cual las teorías del pasado parecen, en general, aproximaciones sucesivas a la descripción del mundo que ofrecen las teorías actuales - p. ej., la teoría de Newton ofrece una visión del universo más parecida a la que tenemos hoy en día que la de Copérnico, y ésta que la de Ptolomeo- (Zamora, 2000, 178).

La historia de la ciencia es como la torre humana que hace la familia de acróbatas en el circo. Los que están arriba ven más lejos que los que están abajo, porque están sobre sus hombros. Cada teoría científica contiene la parte de verdad que puede contemplarse desde la altura de su tiempo.

El concepto de «altura de los tiempos» es una de las ideas pertenecientes a la razón histórica, el método de las ciencias humanas. A las que Ortega propuso la extensión del método de las ciencias naturales, de la razón vital:

No hay historia sin datos, sin hechos comprobados. Pero la historia no consiste en los datos. La misión de éstos es, primero, obligarnos a imaginar hipótesis que los expliquen, que los interpreten porque todo hecho es por sí equívoco, y segundo, confirmar o invalidar esas hipótesis. La perfección lograda en las disciplinas instrumentales de la historia quita a ésta todo pretexto para que no dé el paso decisivo que la instaure como genuina ciencia. Este paso es el empleo del método hipotético que ha permitido constituirse a las demás ciencias empíricas (VII, 514).

La razón histórica consiste en la aplicación de la razón vital al estudio de la historia. Naturalmente, no todos los objetos de la ciencia son históricos, sino sólo aquellos en que el hombre es protagonista. Es decir, que, aunque la ciencia, independientemente de los objetos que estudie, es siempre dialéctica, los objetos mismos no tienen por qué serlo. Sin embargo, en la ciencia histórica objeto y método coinciden, porque la historia es dialéctica, porque está hecha por hom- 
bres, y éstos siempre obran dialécticamente: hicieron esto porque antes hicieron aquello otro, y antes... etc. Ortega esperaba mucho de la razón histórica, porque el pasado es lo único que tenemos, nuestro tesoro (IX, 652-654). «No porque de soluciones positivas al nuevo cariz de los conflictos vitales — la vida es siempre diferente de lo que fue-, sino porque evita cometer los errores ingenuos de otros tiempos» (IV, 203). El pasado nos enseña lo que no hay que hacer, una vez constatada su insuficiencia, la limitación de su acierto.

Que la razón vital sea la razón cotidiana se ve claramente en el hecho de que Ortega esté saltando continuamente de una a otra. Así, por ejemplo, está hablando de la historia, e inmediatamente pasa a contemplar el caso del segundo amor:

Y si ahora pasamos de considerar el ritmo o paso con que la historia cambia, al contenido del cambio mismo, hallamos esta simplísima averiguación: nuestro segundo amor es el que es porque antes sentimos el primero. Un segundo amor es siempre de otro cariz que el primero precisamente porque lleva este dentro de sí, conserva su experiencia. Parejamente, en la ciencia se piensa hoy de una cierta manera porque ayer se pensó de otra. Toda idea es, al cabo, insuficiente; tiene sus defectos, en suma, es más o menos un error. El que la inventa vio solo lo que en ella hay de verdad, pero la generación siguiente que la recibe ya hecha, que no necesita emplear sus energías en descubrirla, percibe su limitación, y o bien la completa y perfecciona o bien la arrumba y niega.

En uno y otro caso la nueva idea es lo que es gracias a la experiencia hecha con la de ayer, gracias a que se tiene presente el error de ayer y se evitan sus defectos. Esto acontece con todo lo humano, individual o colectivo (IX, 5199).

Por otra parte, el que la distinción diltheyana entre «explicación» y «comprensión» esté en Las Atlántidas, de 1924, demuestra cómo no tiene sentido distinguir períodos en Ortega en función de las dos razones, vital e histórica. La razón histórica es la misma razón vital, con la que se inicia su segundo período. Ortega llegó por su cuenta a muchas de las ideas de Dilthey. Estudios recientes sobre fenomenología y hermenéutica están poniendo de manifiesto las profundas afinidades existentes entre Husserl y Dilthey, en contraste con los equívocos interpretativos a que tradicionalmente estábamos acostumbrados, como, por ejemplo, que la fenomenología es antihistórica. Tanto no es así, que Franco Díaz de Cerio ha definido la filosofía de Dilthey como «fenomenología histórica» (157). 
Pero en este pequeño escrito no sólo está Dilthey, sino que, tirando de él, al final asoma Kuhn, al revelar la dificultad de entender culturas alejadas de la nuestra en el tiempo: "Entiende cada época lo que para ella es la verdad. La nuestra entiende la teoría de la relatividad. En cambio, la metafísica medieval ya casi no tiene buen sentido para nosotros y la magia del salvaje carece de él por completo para la conciencia espontánea de nuestros contemporáneos» (III, 310). En realidad, a nivel biográfico nos pasa igual; muchas veces no somos capaces de entender cosas que hemos hecho en el pasado, costándonos mucho ponernos en el pellejo del antepasado nuestro que fuimos: tanto hemos cambiado. Pero de allí venimos, y si no hubiéramos sido lo que fuimos, no seríamos ahora lo que somos. Quiero decir, que por muy inconmensurables que sean las teorías, van de la mano — la teoría padre de la teoría hija — en su paseo por la historia.

De cualquier forma, Ortega parece mostrarse optimista, y creer que en última instancia le es posible al historiador dilatar su experiencia y llegar a entender el sentido de lo que en principio no lo tenía. Finalmente, si La estructura de las revoluciones cientificas suele usarse como apoyo del relativismo, la conclusión final de Las Atlántidas es todo lo contrario, pues cada cultura es una perspectiva verdadera, por más que parcial, un trozo de la realidad.

El que la ciencia cambie no es un argumento contra su verdad. Pero en relación a ella, hay en Ortega una crítica a las ciencias naturales, aunque por otra razón. Pues, en su desarrollo histórico han degenerado, convirtiéndose en mero simbolismo probable y artificio útil, algo que, a su juicio, no puede considerarse ya conocimiento. La física, la otrora ciencia imperial, la envidia de Kant, se ha terminado desvelando como «una ocupación intelectual consistente en evitar conocer aquello de que se ocupa. Lo único que le interesa es averiguar desde qué suposiciones se puede construir una figura de las cosas que nos permita saber utilizarlas mecánicamente» (VII, 278-279). «Por eso se ha perdido miedo a la física, y con el miedo, respeto, y con el respeto, entusiasmo» (VI, 49). La ciencia natural es útil, es servil. Pero servil ¿para qué? La crisis de fin de siglo fue consecuencia de la constatación de que el progreso material no había venido acompañado de progreso moral: «Es cuando menos discutible que la aceleración de los vehículos influya en la perfección esencial de los corazones que en ellos hacen ruta» (II, 163). La ciencia terminó convirtiéndose «en un sólido bloque de "conocimiento", impermeable a los sueńos, deseos y expectativas humanas» (206), escribe, en la misma línea, Feyerabend. Para concluir: «¿Se espera de nosotros que aceptemos pacientemente el hecho de que vivimos en un piojoso universo material, que estamos solos en un gran océano de materia sin vida? ¿No deberíamos intentar 
cambiar nuestra visión de este universo, saliendo del dominio de la física ortodoxa y considerando cosmologías más agradables» (165).

Contenido «desagradable» de la ciencia que, naturalmente, se refleja, en el lenguaje: "Al mismo tiempo los científicos se hicieron más y más distantes, "serios", ansiosos de especial reconocimiento, e incapaces y carentes de la voluntad de expresarse de un modo que todos pudieran entender y del que todos pudieran gozar» (206) La «barbarie del especialismo» es tal, que se pierde la capacidad de hablar civilizadamente (143-149). Ortega también criticó este hermetismo científico, pues una de las dimensiones fundamentales del lenguaje es hacerse entender por los demás (VIII, 277; IX, 632). El filósofo español tuvo siempre en cuenta al oyente o lector; no por "cortesía», como se suele oír, sino por su filosofía «circunstancial», que le obligaba a contar con él.

\section{Conclusión}

La filosofía de la ciencia de Ortega y Gasset incorpora propuestas posmodernas posteriores como el concepto de paradigma de Kuhn o el pluralismo y ludismo de Feyerabend, sin renunciar, sin embargo, al enfoque tradicional de la ciencia, esto es, asegurando su verdad, la tierra firme en que hacer pié y salvarse del naufragio escéptico a que se ve abocada la filosofía constructivista de la ciencia, la nueva filosofía de la ciencia e incluso posicionamientos muy actuales, como el de Giere, que, a pesar de sus esfuerzos, todavía conservan cierto resabio relativista. Tiene razón Muguerza cuando escribe que la razón es «con esperanza, sin esperanza y aun contra toda esperanza sin embargo, nuestro único asidero» (289). Pero no una razón moderna, que no hay ya por donde cogerla, sino otra que cuente — absorba - con las críticas que recibió en el siglo XX.

\section{Bibliografía}

Ortega y Gasset, J. (1983). Obras completas, 12 Vols., Madrid: Revista de Occidente/ Alianza Editorial.

- (1994). Notas de trabajo. Epílogo..., Obras completas: Alianza Editorial.

Bueno, G. (2001). «La idea de ciencia en Ortega», El Basilisco, 31, pp.15-30.

Callebaut, W. (1993). Taking the Naturalistic Turn, Or How Real Philosophy of Science is Done, Chicago: The University of Chicago Press. 
Díaz de Cerio, F. (1959). Dilthey y el problema del mundo histórico, Barcelona: Juan Flors.

Feyerabend, P. (1974). Contra el método. Esquema de una teoría anarquista del conocimiento, Barcelona: Ariel.

García Astrada, A. (1959). "Teoría de la ciencia en Ortega», Revista de la Facultad de Filosofía y Letras, 12, pp. 57-78.

Garrido, M. (1983). «El yo y la circunstancia», Teorema, XIII, 3-4, pp. 309-343.

Giere, R. (1988). Explaining Science. A Cognitive Approach, Chicago: The University of Chicago Press.

- (2006). Scientific Perspectivism, Chicago: The University of Chicago Press.

Martínez Bonati, F. (2000). «El postmodernismo de Ortega y Gasset», Mester, 29, pp. 1-27.

Miquel, M. (1992). «Filosofía de la ciencia en Ortega y Gasset», Logos: Anales del Seminario de Metafísica, n. ${ }^{\circ}$ Extra 1, pp. 127-154.

Molero, J. (1981). «La razón histórica en Ortega», Axerquía, 2, pp. 37-51.

Muguerza, J. (1977). La razón sin esperanza, Madrid: Taurus.

Pellicani, L. (2007). «Ortega y Popper: trayectorias paralelas», Revista de Occidente, 312, pp. 35-56.

Zamora Bonilla, J. (2000). "El naturalismo científico de Ronald Giere y Philip Kitcher: Un ensayo de comparación crítica», Revista de filosofía, 24, pp.169-190.

Recibido: 30/11/2012

Aceptado: 13/12/2012 